\title{
Radiology
}

\section{Evaluation of Liver in Type 2 Diabetes Mellitus Using Unenhanced Computed Tomography}

\author{
Huda Osama, $\mathrm{BSc}^{1,2^{*}}$; Afraa Siddig, $\mathrm{PhD}^{1}$; Awadia Gareeballah, $\mathrm{PhD}^{3,4}$; \\ Moawia Gameraddin, $\mathrm{PhD}^{3}$; Hanady Elyas Osman, $\mathrm{PhD}^{2,5}$ \\ ${ }^{I}$ College of Medical Radiological Sciences, Sudan University of Science and Technology, \\ Khartoum State, Sudan \\ ${ }^{2}$ Medical Imaging Technology Department, Al-Ghad International College for Applied Medical Science, \\ Jeddah, Saudi Arabia \\ ${ }^{3}$ Department of Diagnostic Radiologic Technology, Faculty of Applied Medical Sciences, \\ Taibah University, Al-Madinah Al-Munawara, King Saudi Arabia \\ ${ }^{4}$ Faculty of Radiological Sciences and Medical Imaging, Alzaiem Alazhari University, Khartoum, Sudan \\ ${ }^{5}$ Faculty of Radiological and Nuclear Medicine Science, the National Ribat University, Khartoum, Sudan
}

\begin{abstract}
Background: Chronic liver disease occurs due to different etiologies. Most diabetic patients are unaware that the effective control of hyperglycemia might reduce complications and mortality rates. Fatty liver disease is considered a risk factor of hepatic cirrhosis and cancers.

Methods and Results: We conducted a case-control study to assess the impact of type 2 diabetes mellitus (T2DM) on the liver using a CT scan. A total of 100 patients with T2DM and 96 non-diabetic patients as a control group were selected using a convenient sampling method. There was a significant difference in liver attenuation in diabetic and control groups. The CT attenuation values of the liver, pancreas, and spleen were significantly lower in patients with T2DM than in non-diabetics $(P<0.001)$. There was a significant negative correlation between the duration of T2DM and CT attenuation of the liver, pancreas, and spleen $(P<0.01)$.

Conclusion: The CT attenuation of the liver was significantly lower in T2DM than in the non-diabetic patients, and liver attenuation decreased as the duration of T2DM increased. (International Journal of Biomedicine. 2020;10(4):402-406.)
\end{abstract}

Key Words: diabetes mellitus $\bullet$ nonalcoholic fatty liver disease $\bullet$ liver attenuation $\bullet$ unenhanced computed tomography

\section{Abbreviations}

BMI, body mass index; CT, computed tomography; DM, diabetes mellitus; HS, hepatic steatosis; HU, Hounsfield Unit; HbA1c, glycosylated hemoglobin; L/S, liver-to-spleen ratio; LP, liver-to-pancreas ratio; LLL, left liver lobe; NAFLD, nonalcoholic fatty liver disease; PACS, picture archiving and communication system; RLL, right liver lobe; T2DM, type 2 DM.

\section{Introduction}

Type 2 diabetes mellitus (T2DM) is a metabolic disorder that can affect most parts of the body, including the liver.

*Corresponding author: Mrs. Huda Osama Abdelrahman Suliman, Medical Imaging Technology Department, Al-Ghad International College for Applied Medical Science, Jeddah, Saudi Arabia. E-mail: Yaqin 18@hotmail.com
Insulin resistance mainly causes hyperglycemia, which affects the metabolism of carbohydrates, lipids, and proteins leading to nonalcoholic fatty liver disease (NAFLD). The fatty liver may progress to steatohepatitis, hepatic cirrhosis, fibrosis, and hepatocellular carcinomas. Several studies have found that $\mathrm{DM}$ is associated with several hepatic abnormalities, such as NAFLD, cirrhosis, fibrosis, cancers, acute liver disease, unusual elevated hepatic enzymes, and hepatitis. Furthermore, increased fat accumulation in the hepatocytes may affect insulin 
resistance and end in severe metabolic dysfunction. A fatty liver and hyperglycemia can damage the hepatocytes and lead to severe morbidity and mortality among T2DM patients. ${ }^{(1)}$

CT is considered a reliable method for assessing fatty liver. CT is capable of calculating the liver-to-spleen $(\mathrm{L} / \mathrm{S})$ ratio, which is defined as the ratio of the intensities of the liver parenchyma and splenic texture. It is considered an accurate imaging modality for quantifying HS with $90 \%$ accuracy. ${ }^{(2,3)}$

The estimated CT attenuation values of liver parenchyma on an unenhanced CT scan show a strong correlation with the degree of HS seen on histopathologic examination. The measured CT attenuation value of liver parenchyma on an unenhanced $\mathrm{CT}$ scan has been reported to show a strong association with the severity of HS shown on histopathological analysis. $^{(4)}$

The attenuation of a healthy normal liver on unenhanced CT is denser than the spleen and the hepatic vasculature, and it ranges from $50 \mathrm{HU}$ to $65 \mathrm{HU} .^{(5,6)}$ Non-enhanced CT is established as an accurate imaging method for diagnosing moderate to severe fatty liver than it is for mild conditions of steatosis. HS is diagnosed when liver attenuation is less than spleen attenuation or when liver attenuation less than $48 \mathrm{HU} .^{(6)}$ The degree of HS can be diagnosed when liver attenuation is less than $40-42 \mathrm{HU}$, and $\mathrm{L} / \mathrm{S}$ attenuation ratio is less than 0.8 , or $\mathrm{L} / \mathrm{S}$ ratio difference is equal or less than $10 \mathrm{HU}$ ( $^{(7,8)}$

$\mathrm{CT}$ is a useful modality for measuring fat in the liver for patients at risk of metabolic syndromes, such as T2DM. Therefore, this study aimed to assess the liver in T2DM using unenhanced $\mathrm{CT}$, focusing on assessing $\mathrm{CT}$ attenuation of the diabetic liver, compared to the non-diabetic individuals.

\section{Materials and Methods}

The study was conducted in the Medical Imaging Department - CT scan department in Jeddah Hospitals. This study was approved by the ethics committee of the Sudan University of Sciences and Technology. Written informed consent was obtained from each patient.

The cases were retrospectively studied from the reviewed database of all patients who had undergone abdominal CT examinations from March 2018 to March 2020. The exclusion criteria were fibrosis, alcohol consumption, and history of hepatic surgery. A total of 196 patients were selected using a convenient sampling method. Among them, 100 subjects had T2DM regarded as cases, and 96 were non-diabetics as controls.

Unenhanced CT scans of the liver were performed for all participants included in the study. The abdominal CT examinations were done using TOSHPA CT Machine, at $120 \mathrm{kVp}, 50 \mathrm{~mA}-100 \mathrm{~mA}, 5-\mathrm{mm}$ slice thickness $(1 \mathrm{~mm}$ for Axial, $1 \mathrm{~mm}$ for Coronal). Collimation was $0.5 \times 80$, pitch of 0.8 . Every patient was examined in supine positioning, typically feet first, scanning from above the diaphragm (top of the liver) to the level of the iliac crests. The patients were asked to hold their breath at the end of inspiration.

\section{Attenuation measurements}

We delineated five regions of interest: LLL (segment III), RLL (segment V), RLL (segment VI), middle of the spleen, and the body of the pancreas on the CT scans of each patient. The attenuation measurements were obtained for each ROI, which include a larger area of the liver and spleen. Regions excluded were of non-uniform parenchymal attenuation, including apparent hepatic vessels. The 2D axial and coronal images were used to measure the size of the liver and spleen. All the images were interpreted by a single observer with 15 years of experience in CT scan and PACS.

Statistical analysis was performed using statistical software package SPSS version 23.0 (SPSS Inc, Chicago, IL). For descriptive analysis, results are presented as mean \pm standard deviation (SD). Means of 2 continuous normally distributed variables were compared by independent samples Student's t test. Group comparisons with respect to categorical variables are performed using chi-square test. Pearson's correlation coefficient (r) was used to determine the strength of the relationship between the two continuous variables. A probability value of $P<0.05$ was considered statistically significant.

\section{Results}

The study included 100 patients with T2DM (case group) (54\% males and 46\% females) and 96 non-diabetic patients (control group) (42.7\% males and 57.3\% females). The age of T2DM patients ranged from 31 to 85 years (mean age of $58.91 \pm 11.1$ years); mean BMI was $30.74 \pm 7.25 \mathrm{~kg} / \mathrm{m}^{2}$. The results showed that in T2DM, the mean level of HbA1c was $7.4 \% \pm 1.9 \%$. The mean age of non-diabetic patients was 45.96 years; mean BMI - $27.59 \pm 5.9 \mathrm{~kg} / \mathrm{m}^{2}$ (Table 1).

Table 1.

Characteristics of the study groups

\begin{tabular}{|l|c|c|c|}
\hline \multicolumn{1}{|c|}{ Variables } & $\begin{array}{c}\text { T2DM } \\
\text { patients }\end{array}$ & $\begin{array}{c}\text { Non-diabetic } \\
\text { patients }\end{array}$ & $P$-value \\
\cline { 1 - 3 } Male & $54(54 \%)$ & $41(42.7 \%)$ & \multirow{2}{*}{0.668} \\
\cline { 1 - 3 } Female & $46(46 \%)$ & $55(57.3)$ & \\
\hline Age, years & $58.91)$ & 45.96 & 0.001 \\
\hline BMI, kg/m² & $30.74 \pm 7.25$ & $27.59 \pm 5.90$ & 0.001 \\
\hline HbA1c, $\%$ & $7.47 \pm 1.91$ & -- & \\
\hline Duration, ,years & $14.62 \pm 7.19$ & -- & \\
\hline
\end{tabular}

Concerning T2DM, the study clarified that the attenuation of the liver in the different segments was as follows: $44.62 \pm 9.93 \mathrm{HU}$ in segment III of LLL, $43.46 \pm 9.77 \mathrm{HU}$ in segment V of RLL, and 41.29 $\pm 9.63 \mathrm{HU}$ in segment VI of RLL. The CT attenuation of the spleen was $51.88 \pm 9.13 \mathrm{HU}$, and the pancreas was $34.58 \pm 8.74 \mathrm{HU}$. The liver indexes were $203.08 \pm 22.92 \mathrm{~mm}$ in axial one, $117.15 \pm 4.62 \mathrm{~mm}$ in axial two, and $165.85 \pm 28.75 \mathrm{~mm}$ in coronal one. The spleen indexes were $96.32 \pm 17.50 \mathrm{~mm}$ in axial $1,42.76 \pm 9.71 \mathrm{~mm}$ in axial 2, and $87.84 \pm 20.72 \mathrm{~mm}$ in coronal section (Table 2).

Table 3 summarizes the correlation between attenuation (HU) of liver and spleen and duration of DM. The study 
shows a moderate, negative, significant correlation between the attenuation and DM duration. In contrast, a strong, negative significant correlation was found between pancreas $\mathrm{HU}$ and DM duration $(\mathrm{r}=-574, P<0.01)$. Thus, $\mathrm{CT}$ attenuation decreased as the duration of T2DM increased. $\mathrm{HbAlc}$ values also had a moderate, negative, significant correlation with the liver, spleen, and pancreas attenuation $(P<0.01)$.

\section{Table 2.}

Means measurement for age, BMI, duration, liver $\mathrm{HU}$ and indexes in T2DM patients

\begin{tabular}{|l|c|}
\hline \multicolumn{1}{|c|}{ Variables } & Mean \pm SD \\
\hline LLL, HU (segment III) & $44.62 \pm 9.93$ \\
\hline RLL, HU (segment V) & $43.46 \pm 9.77$ \\
\hline RLL, HU (segment VI) & $41.29 \pm 9.63$ \\
\hline Spleen, HU (middle) & $51.88 \pm 9.13$ \\
\hline Pancreas, HU (body) & $34.58 \pm 8.74$ \\
\hline Liver Index (Axial 1)/mm & $203.08 \pm 22.92$ \\
\hline Liver Index (Axial 2)/mm & $117.15 \pm 14.62$ \\
\hline Liver Index (Coronal)/mm & $165.85 \pm 28.75$ \\
\hline Spleen Index (Axial 1)/mm & $96.32 \pm 17.50$ \\
\hline Spleen Index (Axial 2)/mm & $42.76 \pm 9.71$ \\
\hline Spleen Index (Coronal)/mm & $87.84 \pm 20.72$ \\
\hline L/S ratio & 0.83 \\
\hline L/P ratio & 1.2 \\
\hline
\end{tabular}

Table 3.

Correlation between the duration of $\mathrm{DM}$ and $\mathrm{HU}$ of liver, spleen, and pancreas.

\begin{tabular}{|c|c|c|c|c|c|c|}
\hline \multicolumn{2}{|r|}{ Correlations } & $\begin{array}{l}\text { Liver } \\
\text { (upper) }\end{array}$ & $\begin{array}{c}\text { Liver } \\
\text { (middle) }\end{array}$ & $\begin{array}{l}\text { Liver } \\
\text { (lower) }\end{array}$ & $\begin{array}{c}\text { Spleen } \\
\text { (middle) }\end{array}$ & $\begin{array}{c}\text { Pancreas } \\
\text { (middle) }\end{array}$ \\
\hline \multirow{2}{*}{ 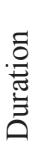 } & Pearson Correlation & $-0.375^{*}$ & $-0.430^{*}$ & $-0.415^{*}$ & $-0.411^{*}$ & $-0.574^{*}$ \\
\hline & Sig. (2-tailed) & 0.000 & 0.000 & 0.000 & 0.000 & $<0.001$ \\
\hline \multirow{2}{*}{$\begin{array}{l}\text { 崖 } \\
\text { 至 }\end{array}$} & Pearson Correlation & $-0.402^{*}$ & $-0.484^{*}$ & $-0.505^{*}$ & $-0.459^{*}$ & $-0.453^{*}$ \\
\hline & Sig. (2-tailed) & 0.000 & 0.000 & 0.000 & 0.000 & $<0.001$ \\
\hline
\end{tabular}

*- Correlation is significant at the 0.01 level (2-tailed).

A comparison of the $\mathrm{HU}$ attenuation of liver and spleen in DM and non-DM patients clarified that the liver's attenuation in diabetic patients is significantly lower than in non-diabetic patients. The CT attenuation of LLL (segment III) in T2DM patients was significantly lower than in nondiabetics $(56.2 \pm 10.69 \mathrm{HU}$ vs. $44.62 \pm 9.93 \mathrm{HU}, P<0.01)$. In
T2DM patients and non-diabetic patients, the $\mathrm{CT}$ attenuation of RLL (segment V) was $43.46 \pm 9.77 \mathrm{HU}$ and $56.02 \pm 10.65 \mathrm{HU}$, respectively, $(P<0.01)$ and $44.62 \pm 9.93 \mathrm{HU}$ and $56.2 \pm 10.69 \mathrm{HU}$, respectively, for segment VI $(P<0.01)$ (Table 4).

Table 4.

Independent sample t-test to compare means of $\mathrm{HU}$ and indexes for liver, spleen, and pancreas in diabetic and non-diabetic patients

\begin{tabular}{|c|c|c|c|}
\hline \multirow[b]{2}{*}{ Variables } & \multicolumn{2}{|c|}{ Mean \pm SD } & $P$-value \\
\hline & $\begin{array}{c}\text { T2DM } \\
\text { patients } \\
(\mathrm{n}=100)\end{array}$ & $\begin{array}{l}\text { Non-diabetic } \\
\text { patients } \\
(\mathrm{n}=96)\end{array}$ & \multirow{6}{*}{$<0.01$} \\
\hline LLL, HU (segment III) & $44.62 \pm 9.93$ & $56.20 \pm 10.96$ & \\
\hline RLL, HU (segment V) & $43.46 \pm 9.77$ & $56.02 \pm 10.65$ & \\
\hline RLL, HU (segment VI) & $41.29 \pm 9.63$ & $55.84 \pm 11.08$ & \\
\hline Spleen, HU (middle) & $51.88 \pm 9.13$ & $47.15 \pm 8.84$ & \\
\hline Pancreas, HU (body) & $34.58 \pm 8.74$ & $45.91 \pm 9.44$ & \\
\hline Liver Index (Axial 1) & $203.08 \pm 22.92$ & $201.95 \pm 20.46$ & \multirow{6}{*}{$>0.05$} \\
\hline Liver Index (Axial 2) & $117.15 \pm 14.62$ & $114.35 \pm 20.03$ & \\
\hline Liver Index (Coronal) & $165.85 \pm 28.75$ & $159.44 \pm 29.55$ & \\
\hline Spleen Index (Axial 1) & $96.32 \pm 17.50$ & $95.2 \pm 15.74$ & \\
\hline Spleen Index (Axial 2) & $42.76 \pm 9.71$ & $42.98 \pm 8.55$ & \\
\hline Spleen Index (Coronal) & $87.84 \pm 20.72$ & $89.19 \pm 16.99$ & \\
\hline
\end{tabular}

The spleen attenuation values in T2DM patients were significantly higher than in non-diabetics $(51.88 \pm 9.13 \mathrm{HU}$ vs. $47.15 \pm 8.84 \mathrm{HU}, P<0.001)$. On the other hand, the pancreatic attenuation values in T2DM were lower than those in nondiabetic patients ( $34.58 \pm 8.74 \mathrm{HU}$ vs. $45.91 \pm 9.44 \mathrm{HU}, P<0.01$ ) (Table 4).

The study found no significant difference in liver and spleen indexes in T2DM patients versus non-diabetic patients. The liver indexes, in general, were slightly higher in T2DMthan in non-diabetic patients. In T2DM patients, the indexes were $203.08 \pm 22.92 \mathrm{~mm}, 117.15 \pm 14.62 \mathrm{~mm}$, and $165.85 \pm 28.75$ $\mathrm{mm}$ in axial 1, axial 2, and coronal section, respectively; in non-diabetic patients the indexes were $201.95 \pm 20.46 \mathrm{~mm}$, $114.35 \pm 20.03 \mathrm{~mm}$, and $159.44 \pm 29.55 \mathrm{~mm}$ in axial 1, axial 2, and coronal section, respectively.

\section{Discussion}

There are many imaging techniques to evaluate the liver. Several previous studies recommended unenhanced CT because of measurements of fat in the useful liver modality for patients at risk of metabolic syndrome, such as diabetes mellitus. CT allows quantitative assessment of the liver attenuation in $\mathrm{HU}$.

In this study, we used CT since it is useful in diagnosing the presence of liver fat and assessing its severity safely. 
The present study revealed that fatty infiltration of the liver was significantly correlated with T2DM. The prevalence of NAFLD is highest in populations with metabolic conditions such as obesity and T2DM. Specifically, T2DM and NAFLD are closely related. A study of patients with T2DM found that fatty liver is significantly associated with DM characteristics, even at younger ages. ${ }^{(9)}$

The present study found that the $\mathrm{CT}$ attenuation values of the liver were significantly decreased in T2DM more than in non-diabetic participants, in agreement with previous studies. ${ }^{(10,11)}$ This decrease in attenuation value of the liver is attributed to the fact that the attenuation value of fat, usually about -100 $\mathrm{HU}$, is much lower than that of soft tissue, which ranges from $30 \mathrm{HU}$ to $40 \mathrm{HU}$. Therefore, the attenuation value of liver parenchyma decreases as HS develops and progresses. This finding indicates that $\mathrm{CT}$ assessment of liver parenchyma on an unenhanced CT scan is accurate since a strong correlation was reported between CT and histopathological analysis regarding the diagnosis of hepatic steatosis. ${ }^{(3)}$

It was found that the $\mathrm{L} / \mathrm{S}$ ratio was 0.83 in T2DM patients. This finding is in agreement with previous studies, which reported approximately similar results. ${ }^{(12,13)}$ On an unenhanced CT scan, the normal liver parenchyma is slightly higher than that of the spleen. As fatty hepatic infiltration progresses, the attenuation value of liver parenchyma decreases, and consequently attenuation of the liver to spleen decreases. ${ }^{(2,3)}$ Therefore, the $\mathrm{L} / \mathrm{S}$ ratio is a significant indicator of a CT assessment of NAFLD.

In this study, we found that a negative correlation existed between the duration of DM and attenuation values of the pancreas, liver, and spleen. As the duration of the DM increased, the attenuation of the liver, pancreas, and spleen decreased significantly $(P<0.001)$. We also found that the most affected organ was the pancreas, which showed a strong, significant negative correlation.

Pancreatic fat density decreased accordingly as the duration of the disease increased. ${ }^{(14)}$ Similarly, Lim et al. ${ }^{(15)}$ stated that T2DM patients had excessive pancreatic fat content, compared to normoglycemic subjects. Ahbab et al. ${ }^{(16)}$ reported that DM correlated with a decrease in the mean $\mathrm{HU}$ values of the pancreas $(P=0.002)$. These decreased attenuation values were attributed to the fact that pancreatic fat content increased in T2DM, resulting in increased fat content in the pancreatic tissue. The negative correlations suggested that the values of these factors increase as the degree of pancreatic fatty infiltration increases. In general, these findings indicate that the duration of T2DM is a strong influencing factor affecting the $\mathrm{CT}$ attenuation of the pancreas, liver, and spleen.

\section{Conclusion}

The study determined that an unenhanced CT scan evaluation of the liver in T2DM is necessary to determine the degree of fatty infiltration. The $\mathrm{CT}$ attenuation values of the liver, pancreas, and spleen were lower in diabetic patients than non-diabetic ones. The attenuation values of the liver, spleen, and pancreas were significantly decreased as the duration of DM increased.

\section{Competing Interests} interests.

The authors declare that they have no competing

\section{Acknowledgments}

We thank all the members of the Radiology Department in Jeddah Hospitals for their help in data collection.

\section{References}

1. Mohamed J, Nazratun Nafizah AH, Zariyantey AH, Budin SB. Mechanisms of Diabetes-Induced Liver Damage: The role of oxidative stress and inflammation. Sultan Qaboos Univ Med J. 2016 May;16(2):e132-41. doi: 10.18295/ squmj.2016.16.02.002.

2. Osawa H, Mori Y. Sonographic diagnosis of fatty liver using a histogram technique that compares liver and renal cortical echo amplitudes. J Clin Ultrasound. 1996 Jan;24(1):259. doi: 10.1002/(SICI)1097-0096(199601)24:1<25::AIDJCU4>3.0.CO;2-N.

3. Matteoni CA, Younossi ZM, Gramlich T, Boparai $\mathrm{N}$, Liu YC, McCullough AJ. Nonalcoholic fatty liver disease: a spectrum of clinical and pathological severity. Gastroenterology. 1999 Jun;116(6):1413-9. doi: 10.1016/ s0016-5085(99)70506-8.

4. Lee DH. Imaging evaluation of non-alcoholic fatty liver disease: focused on quantification. Clin Mol Hepatol. 2017 Dec;23(4):290-301. doi: 10.3350/cmh.2017.0042.

5. Schwenzer NF, Springer F, Schraml C, Stefan N, Machann J, Schick F. Non-invasive assessment and quantification of liver steatosis by ultrasound, computed tomography and magnetic resonance. J Hepatol. 2009 Sep;51(3):433-45. doi: 10.1016/j.jhep.2009.05.023.

6. Valls C, Iannacconne R, Alba E, Murakami T, Hori M, Passariello R, Vilgrain V. Fat in the liver: diagnosis and characterization. Eur Radiol. 2006 Oct;16(10):2292-308. doi: 10.1007/s00330-006-0146-0.

7. Kani KK, Moshiri M, Cuevas C, Lee JH, Mitsumori LM, Kolokythas O. Imaging patterns of hepatic steatosis on multidetector CT: pearls and pitfalls. Clin Radiol. 2012 Apr;67(4):366-71. doi: 10.1016/j.crad.2011.08.023.

8. Mehta SR, Thomas EL, Bell JD, Johnston DG, TaylorRobinson SD. Non-invasive means of measuring hepatic fat content. World J Gastroenterol. 2008 Jun 14;14(22):3476-83. doi: 10.3748/wjg.14.3476.

9. Sakitani K, Enooku K, Kubo H, Tanaka A, Arai H, Kawazu S, Koike K. Clinical characteristics of patients with diabetes mellitus and fatty liver diagnosed by liver/spleen Hounsfield units on CT scan. J Int Med Res. 2017 Jun;45(3):1208-1220. doi: $10.1177 / 0300060517707672$.

10. Iwasaki M, Takada Y, Hayashi M, Minamiguchi S, Haga H, Maetani Y, Fujii K, Kiuchi T, Tanaka K. Noninvasive evaluation of graft steatosis in living donor liver transplantation. Transplantation. 2004 Nov 27;78(10):1501-5. doi: 10.1097/01.tp.0000140499.23683.0d.

11. Hur BY, Lee JM, Hyunsik W, Lee KB, Joo I, Han JK, Choi BI. Quantification of the fat fraction in the liver using dual-energy computed tomography and multimaterial decomposition. J Comput Assist Tomogr. 2014 NovDec;38(6):845-52. doi: 10.1097/RCT.0000000000000142. 
12. Hyodo T, Yada N, Hori M, Maenishi O, Lamb P, Sasaki K, Onoda M, Kudo M, Mochizuki T, Murakami T. Multimaterial Decomposition Algorithm for the Quantification of Liver Fat Content by Using Fast-Kilovolt-Peak Switching Dual-Energy CT: Clinical Evaluation. Radiology. 2017 Apr;283(1):108118. doi: 10.1148/radiol.2017160130.

13. Sakitani K, Enooku K, Kubo H, Tanaka A, Arai H, Kawazu S, Koike K. Clinical characteristics of patients with diabetes mellitus and fatty liver diagnosed by liver/spleen Hounsfield units on CT scan. J Int Med Res. 2017 Jun;45(3):1208-1220. doi: 10.1177/0300060517707672.

14. Jeong JS, Kim MK, Han KD, Hong OK, Baek KH, Song KH, Chung DJ, Lee JM, Kwon HS. The Association between Pancreatic Steatosis and Diabetic Retinopathy in Type 2 Diabetes Mellitus Patients. Diabetes Metab J. 2018 Oct;42(5):425-432. doi: 10.4093/dmj.2017.0107.

15. Lim S, Bae JH, Chun EJ, Kim H, Kim SY, Kim KM, et al. Differences in pancreatic volume, fat content, and fat density measured by multidetector-row computed tomography according to the duration of diabetes. Acta Diabetol. 2014 Oct;51(5):739-48. doi: 10.1007/s00592-014-0581-3.

16. Ahbab S, Ünsal A, Ataoğlu HE, Can TS, Kayaş D, Savaş Y. Prediabetes and Type 2 Diabetes are Independent Risk Factors for Computed Tomography-Estimated Nonalcoholic Fatty Pancreas Disease. Clinics (Sao Paulo). 2019 Oct 28;74:e1337. doi: 10.6061/clinics/2019/e1337. 